\title{
To what extent does the presence of forests and trees contribute to food production in humid and dry forest landscapes?: a systematic review protocol
}

Samson Foli ${ }^{1 *}$, James Reed ${ }^{1}$, Jessica Clendenning ${ }^{1}$, Gillian Petrokofsky ${ }^{2}$, Christine Padoch ${ }^{1}$ and Terry Sunderland ${ }^{1}$

\begin{abstract}
Background: An increasing evidence base is improving our understanding of how forests and trees provide important ecosystem services to agriculture. However, the specific functions and contributions forests and trees make to agricultural systems is far from being fully understood. This review assesses the strength of the evidence that reports how forests and trees contribute to agricultural (food) production in order to prioritize further research for better decision-making. We consider there may be significant gaps in the literature with regard to, 1) Which ecosystem services are provided by forests and trees within a landscape, 2) Over what spatial scales are these services transferred and, 3) To what extent are these services ultimately translated to increased food production? The contributions of trees to agriculture have often been poorly understood and poorly integrated into agriculture and conservation policy and practice.

Methods: The primary question of this systematic review is: To what extent does the presence of forests and trees contribute to food production in humid and dry forest landscapes? The search strategy will employ terms from studies on forests, agroforestry, ecosystem services and agriculture. A scoping exercise in CAB Abstracts, Scopus and ISI Web of Knowledge was used to understand the breadth of ecosystems literature, and further to conduct a preliminary scoping study. An equivalent search in Google Scholar will be used to cross-reference studies retrieved to ensure that relevant studies are not missed. Specialist searches at universities, relevant agricultural and forestry organizations' websites, and a call for unpublished studies will identify important grey literature. Retrieved articles will be screened by title, abstract and full text and inclusion/exclusion exercise will generate the final list of studies. Data from these studies will be extracted using a coding tool. Due to anticipated heterogeneity in the retrieved data, we will group findings into appropriate categories as an initial presentation of the data. Sub group meta-analysis by types of ecosystem services and other appropriate predictors will be conducted to show the positive or negative effects of forests and trees on food production.
\end{abstract}

Keywords: Ecosystem services, Forest, Agroforestry, Food security, Landscape approach, Systematic review

\footnotetext{
* Correspondence: s.foli@cgiar.org

'Centre for International Forestry Research, Bogor, Indonesia

Full list of author information is available at the end of the article
} 


\section{Background}

Ecosystem services are crucial for agricultural production at various scales. Food production systems are often embedded within landscapes that include mosaics of forests, forest fragments, agroforestry systems, and agricultural systems. The spatial configuration of such landscapes influences a range of biophysical processes. Pivotal amongst these are the contributions, often described as ecosystem services, made by forests and trees in landscapes supporting agricultural systems. Ecosystem services are regarded as the structures and functions of terrestrial and marine ecosystems that result in both goods and services that contribute to human wellbeing [1-3].

Ehrlich \& Mooney [4] first coined the term 'ecosystem services' to raise awareness that anthropogenic activity was increasingly degrading habitats and subsequently resulting in the degradation of the functions and services provided by such ecosystems [4]. Since then, there has been growing attention and research on ecosystem services from various analytical angles (see Figure 1). The nature and complexity of assessing ecosystems and the services they provide is reflected in the numerous definitions and classifications that exist [1].

Forest and tree ecosystems underpin the provision of a range of services, and as such, when appropriately managed, can make vital contributions to food production [5]. Ecosystem services provisioning by trees include: habitat for pollinators [6-9], habitat for beneficial species that contribute to natural pest control [10-13], reduced downstream impacts of nutrient run-off [14], and enhanced nutrient availability [15]. These services can be relatively easily assessed at the local and/or farm scale. Meanwhile, at the (sub-)national and global scale (beyond the scope of this review), the contributions of forest ecosystem services include protection of watersheds, carbon sequestration and climate regulation [16] and the evaluation of such services are much more challenging [17]. With reference to Daily et al. [18] and Shibu [19] and Vihervaara et al. [20], we attempted a classification of forest ecosystem services by spatial scale. The classification (see Table 1) helps to identify local and regional ecosystems services provided by forests and trees that are considered relevant to the scope of this systematic review.

Ecosystems research has also established that proximate tree cover can have negative impacts in agricultural systems. Such ecosystem dis-services include damage to crops from pests harbored within the forest, and competition for resources, such as light, water, nutrients and pollinators [21]. Indeed, studies have shown that in landscapes retaining high tree cover, competition effects have reduced pollinator contributions to crops [22]. In contrast, studies in landscapes with heavily deforested areas and low resource availability for pollinators,

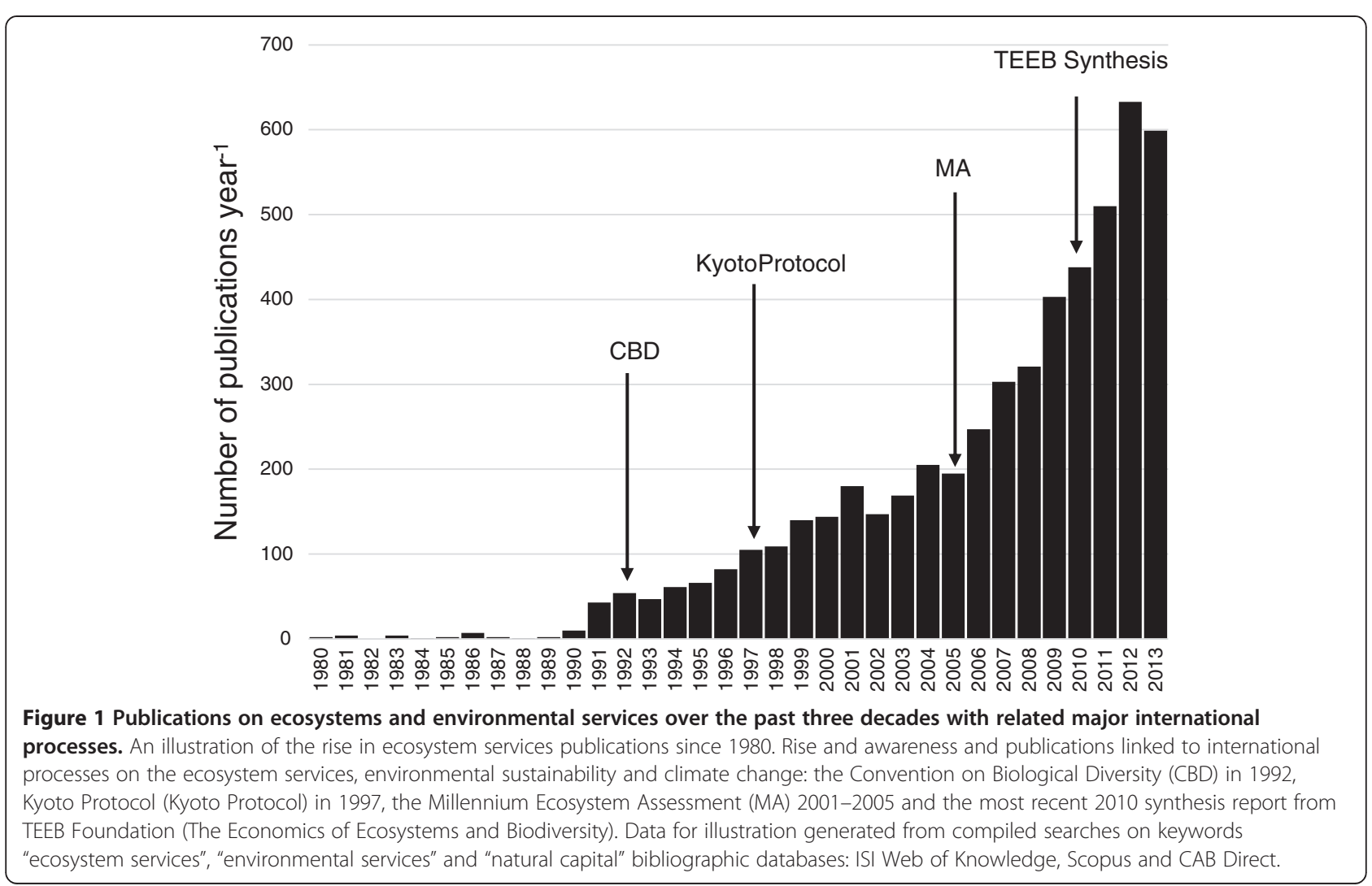


Table 1 Contribution of forests, trees and agroforestry systems to food production systems at different spatial scales

\begin{tabular}{llll}
\hline Ecosystem services & \multicolumn{2}{l}{ Spatial scale } \\
\cline { 2 - 4 } & $\begin{array}{l}\text { Farm/ } \\
\text { local }\end{array}$ & $\begin{array}{l}\text { Landscape/ } \\
\text { regional }\end{array}$ & Global \\
\hline $\begin{array}{llll}\text { Primary production (food and } \\
\text { fodder) }\end{array}$ & $\mathbf{X}$ & & \\
Water retention & $\mathbf{X}$ & & \\
Nutrient cycling & $\mathbf{X}$ & & \\
Pollination services & $\mathbf{X}$ & $\mathbf{X}$ & \\
Habitat for beneficial species & $\mathbf{X}$ & $\mathbf{X}$ & \\
Natural pest control & $\mathbf{X}$ & $\mathbf{X}$ & $\mathbf{X}$ \\
Soil formation & $\mathbf{X}$ & $\mathbf{X}$ & $\mathbf{X}$ \\
Water regulation & $\mathbf{X}$ & $\mathbf{X}$ & \\
Climate regulation & $\mathbf{X}$ & $\mathbf{X}$ & $\mathbf{X}$ \\
Genetic biodiversity & $\mathbf{X}$ & $\mathbf{X}$ &
\end{tabular}

Summarized from Daily et al. 1998, Shibu 2009, and Locatelli 2012: Contributions of forests to agricultural production and food security. Document prepared for discussion at workshop on the value of forests to agriculture. March 2012 Bogor, Indonesia. By the Center for International Forestry Research (CIFOR).

pollinator diversity and abundance in crop patches was high [23].

In the last half century, agricultural expansion has largely come at the cost of natural forests [24] but globally, it is estimated that 46 per cent of total agricultural land still retains at least 10 per cent tree cover [25]. Intensification of agricultural systems towards sole dependence on external inputs and strict management of the production environment has resulted in the compromise of our natural resource base $[17,26]$. For example, the excessive use of inorganic fertilizers and pesticides can greatly reduce the effectiveness of soil biological processes, nutrient cycling and natural enemies for biological pest control [27]. Several such intensified production techniques have caused decline in soil quality, nutrient run-off and water pollution [14]. Evidence from studies reveal that decline in pollinator diversity and sole dependence on honeybee pollinators can contribute to reduced flowering efficacy, fruit set, and yield in pollinator dependent crops [28]. Humans have a shared dependency on both forests and agriculture [29], and as such, agriculture and conservation biology research must adopt a shared responsibility in advancing their sustainability.

Besides the technical advances that downplay the value of nature's services in production systems, agricultural policy and development practice rarely integrate the importance of ecosystems services in food production policy or development initiatives. Instead, priority (indicated by the discrepancies in the literature) often goes for agricultural intensification interventions based on advances in crop and livestock breeding coupled with highly specialized farm management [30]. However, in the past three decades, there has been considerable attention paid to both research and development in alternative agricultural production methods that aim to reconcile nature's services with food, fiber and fuel production at the farm and landscape levels [20]. Figure 2 shows a simple illustration of linkages between ecosystem services provisioning and agricultural systems.

It is also recognized that the disciplines of agriculture and other land uses must integrate efforts to achieve sustainable production, conservation and wider development goals [31,32]. Ecosystems-oriented research is moving from predominantly economic valuation of nature's services [33], to a more integrated landscape approach, in terms of both biophysical and socio-economic benefits society derives from these services [34]. While economic valuations have succeeded in raising awareness of the value of ecosystems, this alone is inadequate and multiple approaches are required. There is increasing awareness that agricultural production takes place in mixed landscapes of managed and 'natural' mosaics, and hence needs to be addressed as a holistic entity [32]. Additionally, forestry and agricultural research must move away from the traditional and straightforward dichotomy between production and conservation towards more integrated land uses in so-called multifunctional landscapes $[35,36]$.

A systematic review summarising the current evidence base on how forests and trees are integral to fostering sustainable agricultural systems is timely. A robust synthesis can both help our understanding of integrative approaches and also identify areas in agriculture and forestry research where knowledge is lacking.

\section{Objectives of the review}

This review will synthesise the scientific knowledge base on forest and tree-based ecosystem services that contribute to crop, livestock and wider food production at the local (farm) level to regional and/or landscape scale (see Table 2). We intend to analyse (both narratively and quantitatively) the available literature on the positive and negative effects of tree cover on productivity of farming systems in terms of crop and livestock yield and natural resource sustainability.

While ecosystems offer important services at the global scale (i.e., carbon sequestration), this is outside the scope of this review. An indicative list of services (shown in Table 1) has been identified as the ecosystem services provided by forests, trees and agroforestry systems at the selected spatial scale and these will serve as a guide for this study. The study intends to retrieve data from the scientific literature that measures the degree of importance of forests and trees. Secondly, we will review how forests also perpetuate dis-services in food production systems. By systematically reviewing 


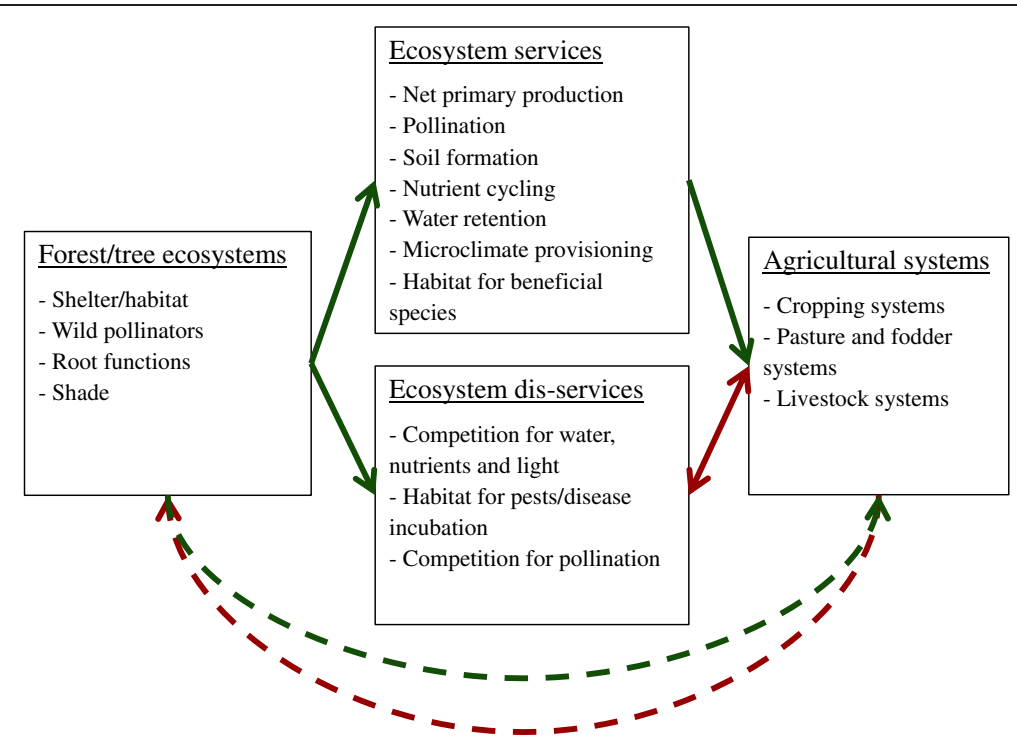

Figure 2 Contribution of ecosystem services and dis-services from trees to agricultural systems. The contribution of forests, trees and agroforestry to food production systems. Trees and forests regulate functions that produce services and goods directly to produce food or can be transformed indirectly to support crop and livestock production. Forests and trees also compete with agriculture for productions resources. Additionally, trees ecosystems may serve as habitat for pests and diseases in in what is often referred to as ecosystem dis-services. Adapted from Zhang et al. 2007.

the literature on both ecosystem services and dis-services, an additional aim of the study is to identify knowledge gaps and make recommendations for future research.

\section{In summary, the review aims to:}

1. Identify and appropriately aggregate studies that investigate the contribution of forests and trees to food (crop and livestock) production systems through ecosystem services and dis-services provisioning at farm level and landscape scale.

2. Analyze the identified studies through quantitative synthesis and meta-analysis techniques to establish the effects of forest and tree presence on food production.

3. Assess the literature to determine if there is a systematic publication bias towards certain ecosystem services and/or the publication of positive results.

4. Use the findings from the analysis to identify knowledge gaps and recommend future research priorities.

\section{Primary question}

To what extent does the presence of forests and trees contribute to food production in humid and dry forest landscapes?

\section{Sub-questions}

1. How do ecosystem services and dis-services impact food production at farm and landscape scale?

2. How do ecosystem services and dis-services affect natural resource management of production resources (water, nutrients, light, pollination, etc.) at farm and landscape scale?

3. What is the state of the scientific evidence base reporting the effects of different ecosystem services and dis-services on food production, in particular relative differences in the amount and/or quality of studies on, for example, humid vs. dry forest regions, diverse agroforestry vs. 'natural' forest systems, different geographical locations, and different types of production systems?

Table 2 Study population, interventions, comparators and outcomes (PICO) relevant to the systematic review question

\begin{tabular}{|c|c|c|c|}
\hline Population & Interventions & Comparators & Outcomes \\
\hline $\begin{array}{l}\text { Farm (local) and landscape (regional) scale } \\
\text { agricultural systems in humid and dry } \\
\text { forests. }\end{array}$ & $\begin{array}{l}\text { Tree or forest } \\
\text { presence. }\end{array}$ & $\begin{array}{l}\text { Tree or forest } \\
\text { absence }\end{array}$ & $\begin{array}{l}\text { Direct and indirect measured effects of tree cover on food production } \\
\text { (crop and livestock yield), resource availability and/or competition, } \\
\text { utilization and/or conservation }\end{array}$ \\
\hline
\end{tabular}




\section{Methods}

\section{Searches}

Experts from invited research institutes and universities met at a workshop held in Noordwijkerhout, Netherlands from 29th September to 2nd October 2013. The discussions held helped to frame the research question, identify key sources of literature and appropriate experts to advise the review team, and consider the potential outputs of the review and how these might address future decisionmaking in agricultural policies.

Preliminary scoping searches were conducted in November 2013 in Web of Knowledge (WoK), Scopus and $C A B$ Abstracts. Main search terms for the review were established during the framing exercise held in the Netherlands. From this workshop, the main terms were identified as "forests", "ecosystem services", "food production systems", "yield" and "resource management". These main terms were taken forward as the foundation for the initial scoping study. Researchers' own knowledge and thesaurus functions (CAB Thesaurus, Agrovoc, and the US National Agricultural Library's (NAL) Agricultural Thesaurus) were applied to expand the main search terms and identify additional terms. The main terms were combined with the Boolean operator 'AND' and this produced 321 hits. Consequently, the main term "ecosystem services" was replaced with specific terms such as "climate regulation", "pollination", etc., and the searches were rerun. This exercise returned over 100 thousand publications in total. To improve the specificity, the individual ecosystem services terms were combined into search strings and this trial retrieved approximately 63 thousand hits. The preliminary search exercise helped narrow down the scope of the review to exclude "genetic services", "hydrological services" and global climate stabilization services such as "carbon sequestration". The decision was made to exclude these topics due to the sheer mass of their respective publication base, and also considering feasibility regarding the resources and time available for the study. The final lists of the review's search terms and strings are presented in Table 3. Supplementary data on the searches is given in Additional file 1.

Search results from all databases used will be exported to Endnote 17 citation manager and cleaned for duplicates. Remaining citations will go through a screening process (guided by the inclusion/exclusion criteria) explained below.

\section{Specialist searches for grey literature}

Unpublished literature is likely to be important for this study and will be captured through websites and/or direct emailing of pre-identified institutions that work on issues related to the scope of the review. A flyer calling for grey literature will also be produced and circulated

Table 3 Final categories of search terms, phrases and strings that evolved from initial scoping

\begin{tabular}{|c|c|}
\hline Main terms & Expanded terms \\
\hline 1. Forest and trees & $\begin{array}{l}\text { *forest* OR tree* OR "humid forest*" OR "dry forest*" OR "tropical forest*" OR agroforest* OR "agro-forest*" OR } \\
\text { "primary *forest*" OR "secondary *forest*" OR "forest fragment*" OR "degrad* *forest*" OR planted forest* }\end{array}$ \\
\hline 2. Ecosystem services & $\begin{array}{l}\text { ecosystem service* OR "ecosystem service*" OR "ecosystem function*" OR "ecolog* service*" OR "environment* } \\
\text { service }^{* "} \text { OR "support* service*" OR "nature* service*" OR "regulat* service*" OR "natur* capital" OR "ecosystem } \\
\text { dis-service*" OR "ecosystem disservice*" }\end{array}$ \\
\hline $2 a$. & $\begin{array}{l}\text { pollinat* OR "animal pollinat*" OR "insect pollinat*" OR "bee pollinat*" OR "wild pollinat*" OR "honey bee*" } \\
\text { NOT "wind pollinat*" OR "pollinat* service*" }\end{array}$ \\
\hline $2 b$. & $\begin{array}{l}\text { Soil* OR "soil regulat*" OR "soil enhanc*" OR "soil protect*" OR "soil fertility" OR "soil quality" OR "soil nutrient*" } \\
\text { OR "soil stabiliz*" OR "plant nutri*" OR "nutrient cycling" OR decompos* OR "nitrogen cycling" OR "nitrogen fix*" } \\
\text { OR "nitrogen captur*" OR "atmosphere* nitrogen fix*" OR "atmosphere* } N^{*} \text { fix*" OR "atmosphere* nitrogen captur" } \\
\text { OR "atmosphere* } \mathrm{N}^{*} \text { captur*" OR erosion control OR "erosion control" OR "water retention" }\end{array}$ \\
\hline $2 c$. & $\begin{array}{l}\text { Pest* OR "Crop pest*" OR "pest control" OR "insect pest*" OR "natural enem*" OR "biological control" OR } \\
\text { biodiversity OR bio-diversity }\end{array}$ \\
\hline $2 \mathrm{~d}$. & "Climate control" OR "climate regulat*" OR microclimate* OR "climate stabili*" OR "microclimate regulat*" \\
\hline 3. Farming systems & $\begin{array}{l}\text { farm* OR agricultur* OR "farm* system*" OR "food produc*" OR "food produc* system*" OR "low input* } \\
\text { agricultur*" OR "low input* farm*" OR "low extern* input*" OR "organic farm*" OR "organic agricultur*" } \\
\text { OR "biolog* farm*" OR "biolog* agricultur*" OR "biodynamic farm** OR "bio-dynamic farm*" OR } \\
\text { "biodynamic agricultur*" OR "bio-dynamic agriculture*" OR agroforest* OR "agro-forest*" OR "evergreen } \\
\text { agricultur" OR "evergreen farm*" OR "swidden system*" OR "swidden agricultur*" OR "swidden farm*" } \\
\text { OR "shifting cultivation" OR "slash and burn" OR "forest* fallow*" OR "permanent fallow*" OR livestock* } \\
\text { OR "livestock produc*" OR "crop-livestock system*" OR "crop-livestock farm*" OR "crop-livestock integrat*" } \\
\text { OR "silvi-pastoral system*" OR "silvi-pastoral farm*" OR "conserv* agricultur*" OR smallholder produc* OR } \\
\text { smallholder agricultur* OR smallholder farm* }\end{array}$ \\
\hline 4. Food production & $\begin{array}{l}\text { Yield* OR "crop yield*" OR "crop produc*" OR "livestock produc*" OR "animal produc*" OR "agricultur* } \\
\text { produc*" OR "food produc" OR "plant produc*" OR "biomass produc*" OR "agricultur* yield*" OR } \\
\text { "farm yield*" OR "sustain* yield" OR "sustain* produc*" OR "resource* manag*" OR "natur* resource* } \\
\text { manag*" OR "food *security" OR "food system*" }\end{array}$ \\
\hline
\end{tabular}


through blog posts, CIFOR social media channels, and distributed at international conferences attended in the early processes of the review. Supplementary data provided as additional file contains the relevant institutions and websites that will be consulted for unpublished literature (see Additional file 2). Links to the flyer and blog post calling for grey literature are given as additional files to the protocol (see Additional file 3).

\section{Internet Searches}

An intended search in Google Scholar will test the comprehensiveness of our main searches. The first 300 returned hits will be assessed and any relevant literature not already retrieved from the prior searches will be added to the reference list. Main search terms ("Forest", "Trees", "Ecosystem services", "Farming systems", and "Food production") will be applied for internet searches.

\section{Study exclusion/inclusion criteria}

Studies will be included in the review if they fulfill the criteria outlined below:

Relevant study subject: studies that measure ecosystem services in agricultural landscapes with tree and/or forest cover. Studies must fall in humid and dry tropics.

Relevant study method/design: studies use relevant, transparent and repeatable quantitative methodology.

Relevant study comparators: relevant comparison between agricultural systems with and without presence of forest and/or tree cover.

Relevant study outcomes: studies measure and report relevant outcomes that show a clear positive, negative or neutral effect of tree/forest presence on ecosystem functions in relevant agricultural landscapes.

A preliminary inclusion/exclusion assessment of a randomly selected 100 articles will be conducted to test consistency between researchers' screening judgment. Cohen's Kappa metrics will be used to indicate a measure of consistency. A consistency co-efficient of 0.6 or greater is usually accepted as sufficient in the literature [37]. First stage of inclusion/exclusion entails screening for relevance of articles by title only. Abstracts of remaining articles will be read leaving a smaller number of articles that will be assessed from full text. The same two researchers will be responsible for entire screening phase. Researchers will record the study screening process and list all articles that are excluded at each stage as required by systematic review guidelines. This will be provided as supplementary material to the full review paper.

1983 is the year we are first aware of the term 'ecosystem services' being used in the scientific literature. However, we acknowledge that studies were conducted prior to this on what we now consider to be ecosystem services. We will include all relevant studies dating back to 1950. Searches will be performed in English only. This decision is based on feasibility of study in terms of available time and resources. We will only include studies that are published in English for the same reasons.

\section{Exclusion Criteria}

Studies will be excluded from this review if they do not meet inclusion criteria or focus on one or more of the following:

- Studies of ecosystem services and dis-services provisioning at (sub)national and global scale.

- Exploratory studies, conceptual frameworks, methods papers.

- General forestry and agricultural policy briefs.

- Studies that publish benefits of trees and forests to food production without (re)presentation of primary data.

- Studies solely on economic evaluation and accounting of ecosystem services.

- Studies outside humid and dry forest regions.

- Studies on the contribution of wind pollination to crop production.

- Studies on ecosystem services and dis-services provisioning in agricultural systems without a link/data on the role of forests and trees.

- Relevant studies but without transparent methodology and/or findings.

\section{Potential effect modifiers and reasons for heterogeneity}

The following are variables that can likely affect outcomes of relevant studies and therefore will be recorded and reported in the full review.

- Classification of forests: length of establishment, species mix, and proximity to an agricultural system.

- Type of agricultural system: type of crop(s) and/or livestock

- Climate and agro-ecological zone classification

- Type of ecosystem service(s) studied

The above is a preliminary list that the researchers intend to amend as further reasons for heterogeneity are identified during the course of the review process. 


\section{Study quality assessment}

Study quality assessment will not form part of exclusion/ inclusion criteria, i.e. all articles that pass full text screening will be included in the preliminary review synthesis. Further, studies will be assessed for quality in order to conduct a meta analysis. Studies will be deemed fit for meta analysis if they present amongst others relevant sample means, samples sizes, standard deviations and/ or standard errors, etc. During quality assessment, studies will be judged into three categories as: 1 ) below acceptable quality, 2) acceptable quality and 3) high study quality. Studies categorized as below acceptable quality (1) will be excluded from the meta analysis. The study quality assessment will be based on:

- Duration of experiment

- Sound experimental design and analysis

- Inclusion of appropriate control treatments

- To what extent random environmental effects are taken into consideration

- Sampling quality (randomization and representativeness) of experimental units

- Number of replications, etc.

If studies are highly interesting but do not provide sufficient data, researchers will contact respective authors to access additional data. In the case that extra information cannot be retrieved, studies will be excluded from the meta analysis.

\section{Data extraction strategy}

The following information will be recorded for all included studies/publications:

- Title

- Author(s)

- Journal

- Date of publication

- Location of study

- Scope of study (local/farm or landscape/regional)

- Agro-ecological and climatic zone classification (dry forest region, semi-arid Sahel, etc.)

- Type of ecosystem service(s) or dis-service(s) studied.

- Methodology (i.e. experimental, research station trials, farmer fields or participatory trials)

- Type of study (i.e. primary, review or meta-analysis)

- Type of food production system (e.g. home garden, agroforestry system, monocropping, crop-livestock systems, etc.)

- Dominant landscape configuration (e.g. forest fragments, degraded forests, swidden systems, pastoral systems, etc.)

- Proximity to forests and/or tree cover
- Type of outcome and effects measured (crop/ livestock yields, tree competition for resources, pollination efficacy, reduced pest damage, etc.)

- Sample means, standard deviations/errors and correlations of recorded outcomes/effects

- Other effect modifiers (e.g. impact of variables other than those studied)

Where data are not completely recorded or missing within the retrieved studies, the reviewers will contact the lead author to see if original data can be obtained. Studies and publications with incomplete data will be excluded from the review.

\section{Data synthesis and presentation}

The systematic review will first and foremost present a narrative synthesis of the data in appropriate categories. Data will be synthesized by region of study, types of forests, types of agricultural systems, types of ecosystem services and dis-services, focus of studies (i.e. on natural resource management, biomass production, yield, etc.). Subsequently, a meta analysis on sub groups of the data will be conducted for example on all studies that measure tree competition effects on crops, or nutrient cycling in agroforestry systems, or water/nutrient/light competition in alley cropping systems, etc. A sub group meta analysis is envisioned due to the broad scope of ecosystem services in this review. Within the meta analysis, a publication bias test will be conducted to elucidate if certain ecosystem services receive more publications and why. Such a test will also reveal if researchers and publishers systematically report studies that show positive results over others (i.e. neutral to negative results). The aim of the publication bias tests is to help in the identification of knowledge gaps and propose recommendations for further research.

\section{Dissemination strategy}

The full systematic review will be published as a peer reviewed article in EE. Findings will be disseminated at international conferences on agriculture and forestry research. The systematic review is additionally intended for a wider audience and will be disseminated as CIFOR Occasional Paper and in the form of blog posts and policy briefs.

\section{Additional files}

Additional file 1: Search terms and combinations developed through study.

Additional file 2: Relevant organization websites consulted directly for grey literature.

Additional file 3: Call for grey and unpublished literature. 


\section{Competing interests}

The authors declare that they have no competing interests.

\section{Authors' contributions}

SF, TS, and JR, Conceived the study. SF and TS Coordinated the study. SF, JR, JC, Designed and drafted the manuscript. TS, GP and CP, Provided feedback and input to manuscript. All authors read and approved the manuscript.

\section{Acknowledgements}

This study is funded by the CIFOR Evidence-Based Forestry (EBF) initiative, supported through the United Kingdom's Department for International Development (DfID). The authors thank the advisory group for their feedback on the protocol and the experts that attended the stakeholder workshop at the launch of the review.

\section{Author details}

${ }^{1}$ Centre for International Forestry Research, Bogor, Indonesia. ${ }^{2}$ Biodiversity Institute, University of Oxford, Oxford, UK

Received: 7 March 2014 Accepted: 18 June 2014

Published: 29 July 2014

\section{References}

1. Boyd J, Banzhaf S: What are ecosystem services? The need for standardized environmental accounting units. Ecol Econ 2007, 63:616-626.

2. Daily GC: Nature's services: societal dependence on natural ecosystems. Washington DC: Island Press; 1997.

3. Fisher B, Kerry Turner R: Ecosystem services: Classification for valuation. Biol Conserv 2008, 141:1167-1169.

4. Ehrlich PR, Mooney HA: Extinction, substitution, and ecosystem services. Bioscience 1983, 33:248-254.

5. Metzger MJ, Rounsevell MDA, Acosta-Michlik L, Leemans R, Schröter D: The vulnerability of ecosystem services to land use change. Agric Ecosyst Environ 2006, 114:69-85.

6. Balvanera P, Kremen C, Martínez-Ramos M: Applying Community Structure Analysis To Ecosystem Function: Examples From Pollination And Carbon Storage. Ecol Appl 2005, 15:360-375.

7. Klein A-M, Vaissière BE, Cane JH, Steffan-Dewenter I, Cunningham SA, Kremen C, Tscharntke T: Importance of pollinators in changing landscapes for world crops. Proc R Soc B Biol Sci 2007, 274:303-313.

8. Kremen C, Williams NM, Thorp RW: Crop pollination from native bees at risk from agricultural intensification. Proc Natl Acad Sci 2002, 99:16812-16816.

9. Ricketts TH: Tropical Forest Fragments Enhance Pollinator Activity in Nearby Coffee Crops Fragmentos de Bosque Tropical Incrementan la Actividad de Polinizadores en Cultivos de Café Cercanos. Conserv Biol 2004, 18:1262-1271.

10. Bale JS, van Lenteren JC, Bigler F: Biological control and sustainable food production. Philos Trans R Soc Lond B Biol Sci 2008, 363:761-776.

11. Karp DS, Mendenhall CD, Sandí RF, Chaumont N, Ehrlich PR, Hadly EA, Daily GC: Forest bolsters bird abundance, pest control and coffee yield. Ecol Lett 2013, 16:1339-1347.

12. Klein A-M, Steffan-Dewenter I, Tscharntke T: Rain forest promotes trophic interactions and diversity of trap-nesting Hymenoptera in adjacent agroforestry. J Anim Ecol 2006, 75:315-323.

13. Pickett CCH, Bugg RL: Enhancing biological control: habitat management to promote natural enemies of agricultural pests. California: Univ of California Press; 1998.

14. Logan TJ: Agricultural best management practices for water pollution control: current issues. Agric Ecosyst Environ 1993, 46:223-231.

15. Power AG: Ecosystem services and agriculture: tradeoffs and synergies. Philos Trans R Soc Lond B Biol Sci 2010, 365:2959-2971.

16. Daily GC, Matson PA: Ecosystem services: From theory to implementation. Proc Natl Acad Sci 2008, 105:9455-9456.

17. de Groot RS, Alkemade R, Braat L, Hein L, Willemen L: Challenges in integrating the concept of ecosystem services and values in landscape planning, management and decision making. Ecol Complex 2010, 7:260-272.

18. Daily G, Dasgupta P, Bolin B, Crosson P, Du Guerny J, Ehrlich P, Folke C, Jansson A, Jansson B-O, Kautsky N: Food production, population growth, and environmental security. :Fondazione Eni Enrico Mattei; 1998.

19. Jose S: Agroforestry for ecosystem services and environmental benefits: an overview. Agroforest Syst 2009, 76:1-10.
20. Vihervaara P, Rönkä M, Walls M: Trends in Ecosystem Service Research: Early Steps and Current Drivers. AMBIO 2010, 39:314-324.

21. Zhang W, Ricketts TH, Kremen C, Carney K, Swinton SM: Ecosystem services and dis-services to agriculture. Ecol Econ 2007, 64:253-260.

22. Boreux V, Kushalappa CG, Vaast P, Ghazoul J: Interactive effects among ecosystem services and management practices on crop production: Pollination in coffee agroforestry systems. Proc Natl Acad Sci 2013, 110:8387-8392.

23. Jha S, Vandermeer JH: Impacts of coffee agroforestry management on tropical bee communities. Biol Conserv 2010, 143:1423-1431.

24. Gibbs HK, Ruesch AS, Achard F, Clayton MK, Holmgren P, Ramankutty N, Foley JA: Tropical forests were the primary sources of new agricultural land in the 1980s and 1990s. Proc Natl Acad Sci 2010, 107:16732-16737.

25. de Foresta H, Somarriba E, Temu A, Boulanger D, Feuilly H, Gauthier M: Toward the assessment of trees outside forests. Rome: FAO; 2013.

26. Turner CE, Snaddon LJ, Ewers MR, Fayle MT, William AF: The Impact of Oil Palm Expansion on Environmental Change: Putting Conservation Research in Context. ; 2001

27. Brussaard L, Caron P, Campbell B, Lipper L, Mainka S, Rabbinge R, Babin D Pulleman M: Reconciling biodiversity conservation and food security: scientific challenges for a new agriculture. Curr Opin Environ Sustain 2010 2:34-42.

28. Garibaldi LA, Steffan-Dewenter I, Winfree R, Aizen MA, Bommarco R, Cunningham SA, Kremen C, Carvalheiro LG, Harder LD, Afik O, Bartomeus I, Benjamin F, Boreux V, Cariveau D, Chacoff NP, Dudenhöffer JH, Freitas BM, Ghazoul J, Greenleaf S, Hipólito J, Holzschuh A, Howlett B, Isaacs R, Javorek SK, Kennedy CM, Krewenka KM, Krishnan S, Mandelik Y, Mayfield MM, Motzke I, et al: Wild Pollinators Enhance Fruit Set of Crops Regardless of Honey Bee Abundance. Science 2013, 339:1608-1611.

29. McKenzie F: Pathways to collaborative action: transforming agricultural, land and food systems. ; 2013.

30. Tscharntke T, Klein AM, Kruess A, Steffan-Dewenter I, Thies C: Landscape perspectives on agricultural intensification and biodiversity - ecosystem service management. Ecol Lett 2005, 8:857-874.

31. Sunderland TCH: Food security: why is biodiversity important? Int For Rev 2011, 13(3):265-274.

32. Perfecto I, Vandermeer JH, Wright AL: Nature's matrix: linking agriculture, conservation and food sovereignty. London: Earthscan; 2009.

33. Costanza R, d'Arge R, de Groot R, Farber S, Grasso M, Hannon B, Limburg K, Naeem S, O'Neill RV, Paruelo J: The value of the world's ecosystem services and natural capital. Ecol Econ 1998, 25:3-15

34. Kremen C, Ostfeld RS: A call to ecologists: measuring, analyzing, and managing ecosystem services. Front Ecol Environ 2005, 3:540-548.

35. Sayer J, Sunderland T, Ghazoul J, Pfund J-L, Sheil D, Meijaard E, Venter M, Boedhihartono AK, Day M, Garcia C, van Oosten C, Buck LE: Ten principles for a landscape approach to reconciling agriculture, conservation, and other competing land uses. Proc Natl Acad Sci 2013, 110:8349-8356.

36. Scherr SJ, MCNeely JA: Biodiversity conservation and agricultural sustainability: towards a new paradigm of 'ecoagriculture' landscapes. Philos Trans R Soc Lond B Biol Sci 2008, 363:477-494.

37. Pullin AS, Knight TM: Support for decision making in conservation practice: an evidence-based approach. J Nat Conserv 2003, 11:83-90.

doi:10.1186/2047-2382-3-15

Cite this article as: Foli et al:: To what extent does the presence of forests and trees contribute to food production in humid and dry forest landscapes?: a systematic review protocol. Environmental Evidence 2014 3:15 